\title{
Primary supratentorial intracerebral malignant paraganglioma
}

\author{
Ahmed A. Al Jishi, Boleslaw Lach, Ali Elgheriani, Edward Kachur, Aleksa Cenic \\ Department of Surgery, Division of Neurosurgery, Hamilton General Hospital, McMaster University, Hamilton, Ontario L8L 2X2, Canada.
}

\section{A B S T R A C T}

Paragangliomas are extra-adrenal neuroendocrine tumors that derive from neural crest. In general, they are benign tumors but few cases had shown a tendency to metastasize. Malignant forms have been reported previously with intracranial metastasis from duodenal origin, but primary intracranial origin represents a rare and unusual location for such tumors. Here, we report a rare case of a 48-year-old lady who presented with symptomatic right-sided insular mass with negative metastatic work up. A complete surgical resection had been done with an unexpected diagnosis of primary gangliocytic paraganglioma with malignant features.

Key words: Brain, chemodectoma, gangliocytic paraganglioma, intracerebral, intracranial

\section{INTRODUCTION}

Paragangliomas are rare neuroendocrine tumors. They arise from the paraganglia distributed along the paravertebral sympathetic chains and related ganglia, as well as from the parasympathetic paraganglia such as aortic body, carotid body, and vagal nerve. As a result of their neuroectodermal origin, few paragangliomas can be functional. Hence, autonomic dysfunctional symptoms may occur such as excessive sweating, hypertension, and tachycardia secondary to vasoactive substances release. They are known to be benign tumors with WHO Grade I. However, around 5-10\% of them may transform malignant along the course of the disease. ${ }^{[1]}$

Paraganglioma may also arise from intracranial or intra-spinal origin. Several explanations were proposed for their existence which include possible growth from ganglionic cells, growth from paraganglia associated with blood vessels or growth from embryonic neuroepithelial rest. ${ }^{[2]}$ They have a tendency to grow in the sellar/parasellar region or cauda equina region. However, the intraparenchymal growth of paraganglioma is uncommon with seldom reported cases in the literature. An unusual case of primary

\begin{tabular}{|l|l|}
\hline \multicolumn{3}{|c|}{ Access this article online } \\
\hline Quick Response Code: & \\
\hline & Website: \\
\hline & www.nnjournal.net \\
\hline
\end{tabular}

intraparenchymal paraganglioma with malignant features was encountered lately at our center. The case is considered to be the first of its kind, and it does reflect the potential risk for malignant primary growth of paraganglioma within the brain parenchyma. A review of the literature for intracranial supratentorial paragangliomas along with the predisposing genetic mutation will be discussed.

\section{CASE REPORT}

A 48-year-old healthy female presented to the emergency department with 1-week history of headache and slurred speech. She noticed that her balance had got worse 3 days prior to presentation. On examination, she was noticed to be ataxic with left sided pronator drift and left lower facial asymmetry. The initial computed tomography (CT) scan of her brain showed an iso-dense mass in the right sub-insular area measuring $3.6 \mathrm{~cm} \times 4.1 \mathrm{~cm} \times 3.7 \mathrm{~cm}$, along with perilesional vasogenic edema and mass effect over adjacent structures [Figure 1]. There was no evidence of calcification or hemorrhagic foci within the lesion. It carried slightly low intensity signal in T1-weighted image with heterogenous signal intensity in T2-weighted image. The lesion was well-demarcated and had homogenous gadolinium uptake with restricted diffusion in diffusion-weighted image/apparent diffusion coefficient map [Figure 2].

The patient was admitted to the hospital for a right-sided fronto-parieto-temporal craniotomy for tumor resection guided by neuronavigation. Intraoperatively, the tumor

Corresponding Author: Dr. Ahmed A. Al Jishi, Department of Surgery, Division of Neurosurgery, Hamilton General Hospital, McMaster University, 237 Barton St East, Hamilton, Ontario L8L 2X2, Canada. E-mail: dr_aljishi@yahoo.com 
was firm in consistency and very vascular in nature but eventually we were able to achieve gross total resection. The early postoperative course was unremarkable for any neurological deficits until patient deteriorated few hours thereafter and had asymmetric blown pupils. Owing to the urgency of the case, the patient was taken for surgery with a provisional diagnosis of postoperative bleeding. Surgical re-exploration was done, and large intracerebral hematoma within the tumor bed was evacuated. The patient, unfortunately, woke up postoperatively with dense left sided hemiplegia [Figure 3].

Microscopic examination of the tumor revealed nests of highly pleomorphic, spindle, epithelioid,

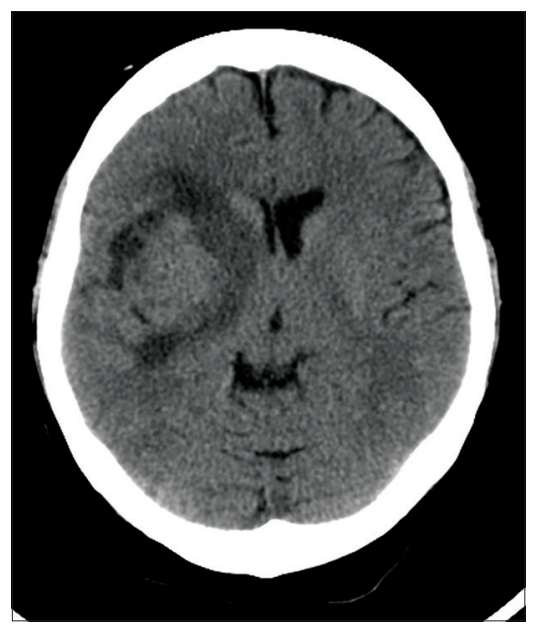

Figure 1: Preoperative plain computed tomography head shows a right-sided isodense lesion within the insular region and large atypical cells with prominent nuclei and nucleoli [Figure 4a]. Abnormal mitotic figures and apoptotic nuclei were common. The tight collections of neoplastic cells were surrounded by rich fibrovascular stroma forming the architectural patterns of "Zellballen". The majority of the neoplastic cells were strongly positive for chromogranin, synaptophysin (SYN), and neuron-specific enolase, and focally for tyrosine hydroxylase [Figure 4b]. Ganglionic cells displayed strong cytoplasmic reaction for SYN and less often tubulin [Figure 4c]. Glial fibrillary acidic protein showed very strong reaction in the cells outlining the edges of the neoplastic congregates, in a pattern seen in sustentacular cells of extracranial paragangliomas [Figure 4d]. The rest of the immunohistochemistry is outlined in Table 1.

At this point, an extensive metastatic work up had been done which included CT of her chest, abdomen, and pelvis, as well as mammogram. Due to the fact that this tumor has been frequently originating from the duodenum, a duodenal scope was also performed. The analysis resulted negative for any primary lesions. As some paragangliomas can be functionally active, serum and urine metanephrines, and catecholamines were investigated and resulted also negative. Given these results and the pathological features of the resected tumor, the assumption was made being a primary malignant gangliocytic paraganglioma. The patient was approached in a multidisciplinary team including the radiation oncology and offered local tumor bed radiation. Due to low karnofsky performance
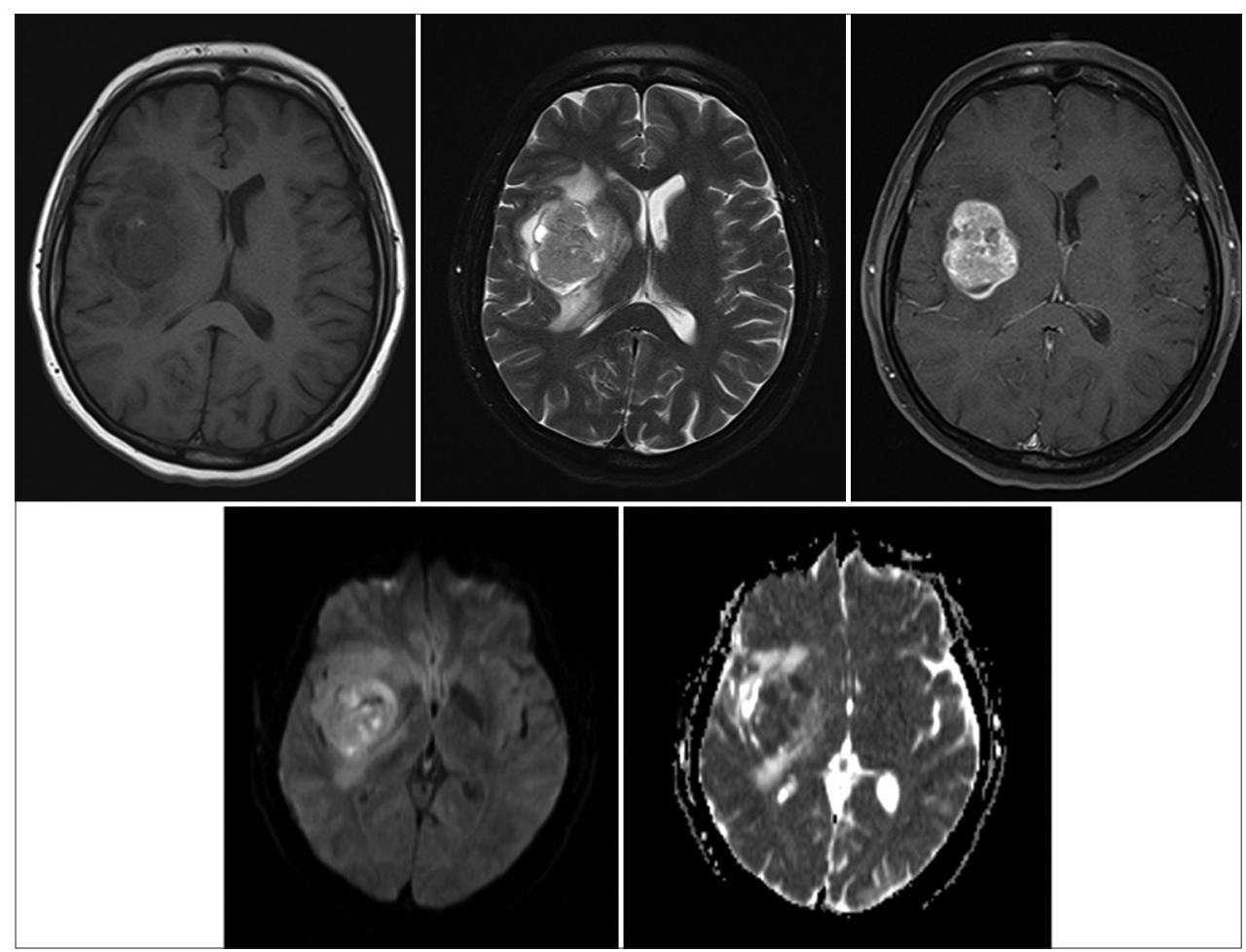

Figure 2: A well-circumscribed tumor that is hypointense in T1-weighted image with heterogeneous texture in T2-weighted image. The lesion was homogenously enhancing post-gadolinium with restricted diffusion 


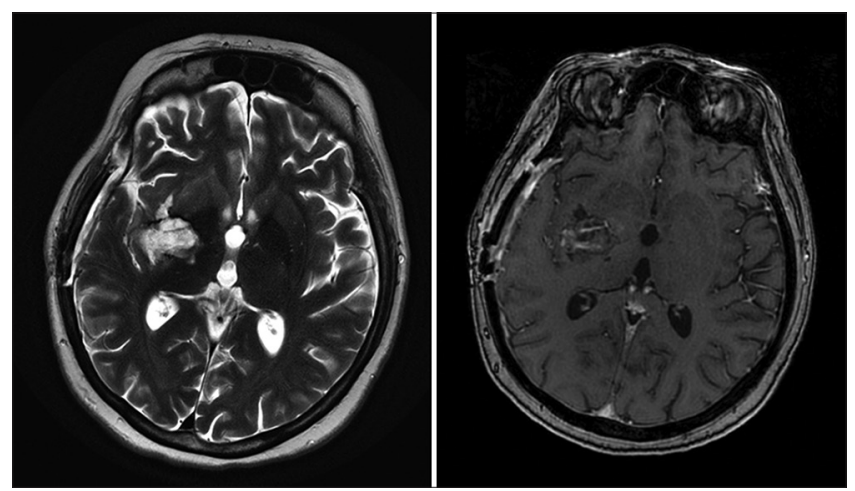

Figure 3: Brain magnetic resonance imaging after 6 weeks from surgery depicts a tumor bed cavity with complete resection. A slight gadolinium uptake was seen within the tumor cavity which represents remnant of fibrillary surgi-cells packing (ethicon) from the second surgery

scale (KPS) of 30, the radiation treatment was deferred until the patient gains more functional strength. She remained stable along with no tumor recurrence on serial follow-up magnetic resonance imaging.

Unfortunately, 12 months postoperatively she presented with a $5 \mathrm{~cm} \times 5 \mathrm{~cm}$ ipsilateral enhancing lesion associated with mass effect. Although she was asymptomatic, we opted for surgical resection given the size of the mass that would interfere with radiation therapy. As expected, the pathological work up revealed similar findings to previously resected tumor. Although her surgical resection went uneventful, she continued to decline her functions with lower KPS, which affected the delivery of radiation treatment. She was referred eventually into palliative care unit and died after 2 months from her second surgery.

\section{DISCUSSION}

Paragangliomas are neural crest-derived tumors that originate in the paraganglia of the autonomic nervous system. Although they are usually considered benign growths, but occasionally malignant forms may occur. They can be functional lesions with active release of catecholamines upon manipulation to result in hemodynamic alterations. The incidence of paraganglioma is frequently reported in combination with pheochromocytoma owing to its rareness along with analogous histological features. The combined annual incidence in United States, for instance, is 500-1600 cases per year with 50\% of them present with hypertension. ${ }^{[3]}$ Paragangliomas are usually sporadic but genetic and syndromic associations have been described. In about 27-32\% cases of paraganglioma, genetic mutations have been discovered among which the succinate dehydrogenase complex mutation is considered one of the most commonly affected genes. ${ }^{[4,5]}$ In addition, several recent works have also correlated the SDHB gene mutation and the malignant behavior of paragangliomas. ${ }^{[6-9]}$

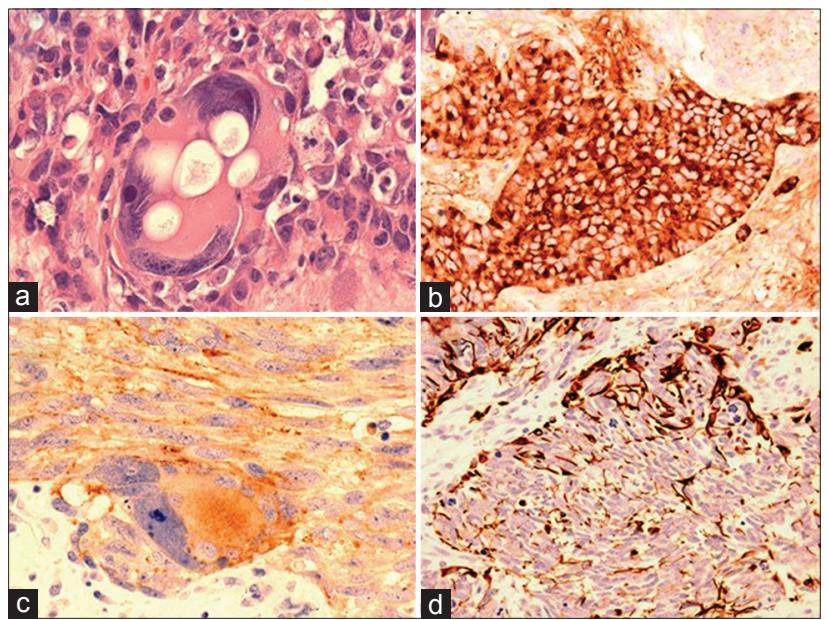

Figure 4: (a) Large neoplastic ganglionic cell with prominent nucleoli and cytoplasmic vacuolation HE; (b) strong chromogranin immunoreactivity in epitheliod tumor cells; (c) cytoplasmic synaptophysin immunoreactivity in a large ganglionic cell and the processes of the adjacent tumor cells; (d) glial fibrillary acidic protein immunoreaction accentuated at the periphery of the tumor nes characteristically seen in sustentacular paraganglioma cells

There have been only 37 reported cases of primary intracranial supratentorial paragangliomas since 1960, and they all harbor benign growth features [Table 2].

In this manuscript, we have excluded from our review all intracranial metastatic paragangliomas and lesions originated in the infratentorial compartment. We found that the mean age of presentation is 47 with 1:1.3 female:male ratio. In around three-quarter of these cases, the sellar/parasellar region was the most common location with symptoms of headache, opthalmoplegia, and endocrinopathy. ${ }^{[43]}$ Again, the benign behavior was a character of all of them with few cases required radiation therapy for incomplete resection.

In term of intraparenchymal origin, only three cases had been reported and were harboring benign pattern. Their location within the brain represents a rare condition. Reithmeier et al. ${ }^{[23]}$ had reported the first case of primary paraganglioma in the insular region. This patient was successfully treated with a complete gross total resection, but dense left sided hemiplegia had occurred postoperatively secondary to cerebral vasospasm. In another case, a left temporal melanotic paraganglioma had developed in a patient who was treated previously with chemotherapy and radiotherapy for langerhans cell histiocytosis. ${ }^{[35]}$ The lesion was partially resected followed by postoperative radiation treatment. The third case had occurred in premotor region, and it was resected completely with the patient remaining stable at short-term follow-up. ${ }^{[38]}$

In this report, we presented a unique case of paraganglioma in which primary intraparenchymal growth with malignant features and ganglionic 
Table I: Immunohistochemical evaluation result for primary malignant ganglionic paraganglioma

\begin{tabular}{llll}
\hline Antibody & Distributor & Abbreviation (dilution) & Immunoreactivity \\
\hline Neurofilament MAb & DAKO & NF $(1: 400)$ & - \\
Neural CAM & DAKO & CD56 (undiluted) & +++ \\
$\beta$-tubulin & SIGMA & BTUB (1:5000) & F++ \\
Synaptophysin MAb & DAKO & SYN (1:25) & ++ \\
Chromogranin A MAb & DAKO & CHRG (1:100) & ++ \\
Calretinin Poly Ab & Invitrogen & CAL (1:200) & F+ \\
Neuron-specific enolase & DAKO & NSE (undiluted) &,+++ \\
S100 protein & DACO & S100 (1:4000) & - \\
Epithelial membrane antigen MAb & DACO & EMA (1:100) & - \\
Keratins & DACO & CAM5.2, AE1/AE3 (undiluted) & - \\
& & & ++ sustentacular c. \\
GFAP Poly Ab & DAKO & GFAP (1:3000) & + sustentacular C. \\
Anti-human melanosome & DAKO & HMB 45 (undiluted) & - \\
Desmin & DACO & DSM (undiluted) & - \\
p53 & DAKO & p53 (1:200) & + \\
Ki-67 MAb & DAKO & Ki-67 (1:1000) & +++
\end{tabular}

GFAP: glial fibrillary acidic protein; CAM: cell adhesion molecule; MAb: monoclonal antibody

Table 2: Literature review for intracranial supratentorial primary paraganglioma

\begin{tabular}{|c|c|c|c|c|c|}
\hline Author & Age (gender) & Presentation & Location & Treatment & Outcome \\
\hline Kruse, $1960^{[10]}$ & 68, male & Behavioral changes & Middle fossa & Resection & Improved \\
\hline Smith et al., $1966^{*[11]}$ & 17, male & Headache & Pineal region & Resection & Moderate disability \\
\hline Chytil, $1967^{[12]}$ & 46 , male & Visual loss, hypopituitarism & Sellar/suprasellar & Resection + RT & No progression \\
\hline Bilbao et al., 1978[13] & 37 , male & Delayed growth & Sellar & Resection & - \\
\hline Ho et al., $1982^{[14]}$ & 65 , male & Diplopia & Cavernous sinus & Resection & Moderate disability \\
\hline Prabhakar et al., 1984[15] & 7, female & Ophthalmoplegia & Parasellar & Resection + RT & - \\
\hline \multirow[t]{2}{*}{ Steel et al., $1993^{[16]}$} & 44 , female & Headache & Sellar & Resection + RT & No progression \\
\hline & 41 , female & Headache, ptosis & Sellar & Resection + RT & No progression \\
\hline Flint et al., $1993^{[17]}$ & 17 , female & Visual defect & Sellar & Resection & - \\
\hline Scheithauer et al., $1996^{[18]}$ & 14 , male & Visual defect & Sellar/parasellar & Resection + RT & Left hemiparesis \\
\hline Nishitani et al., 1996*[19] & 41 , female & Amenorrhea & Parasellar & Resection & Good recovery \\
\hline Noble et al., $1997^{[8]}$ & 71, male & Visual defect & Sellar & Resection & - \\
\hline Mokry et al., $1998^{[9]}$ & 76 , female & Visual defect & Sellar & Resection & Unchanged \\
\hline Caro et al., $1998^{[20]}$ & 84 , male & Memory loss & Sellar/suprasellar & Resection & - \\
\hline Sambaziotis et al., 1999[21] & 54, male & Visual defect & Sellar & Resection & No progression \\
\hline Yamauchi et al., 1999 ${ }^{[22]}$ & 56 , female & Headache & Frontal fossa & Resection & No progression \\
\hline Reithmeier et al., 2000[23] & 42 , male & Seizure & Insula & Resection & Hemiparesis \\
\hline Laquis et al., $2001^{[24]}$ & 15 , female & Occulomotor palsy & Middle fossa & Resection + RT & Improved \\
\hline Salame et al., $2001^{[25]}$ & 48 , female & Oligomenorrhea & Sellar/parasellar & Resection & No progression \\
\hline Hertel et al., 2003[26] & 51 , female & Facial paresis & Middle fossa & Resection + RT & Occulomotor palsy \\
\hline Yokoo et al., 2003[27] & 52 , female & Behavioral changes & Suprasellar & Resection & - \\
\hline Arkha et al., 2003 & 58 , female & Endocrine dysfunction & Sellar/parasellar & Resection & - \\
\hline Riopel et al., 2004 & 66 , male & Diplopia & Parasellar & Biopsy & - \\
\hline Naggara et al., 2005 $5^{[30]}$ & 47 , male & Visual defect & Suprasellar & Resection & - \\
\hline Zorlu et al., 2005 & 37 , male & Visual defect & Sellar/suprasellar & Resection + RT & - \\
\hline Boari et al., 2006[32] & 52, male & Brain ischemia & Sellar & Resection & Pituitary dysfunction \\
\hline Peltier et al., 2007[33] & 51 , female & Occulomotor palsy & Parasellar & Resection & - \\
\hline Sinha et al., 2008 ${ }^{[34]}$ & 18, male & Visual defect & Sellar & Resection + RT & $\begin{array}{l}\text { Skull, scalp and femur } \\
\text { metastasis }\end{array}$ \\
\hline Yoo et al., 2008 & 21 , female & Headache & Temporal lobe & Resection + RT & - \\
\hline Ozüm et al., 2008[36] & 70 , male & Headache & Sellar/parasellar & Resection + RT & - \\
\hline Lu et al., 2009[5] & 81, male & Visual change & Sellar/suprasellar & Resection & $\begin{array}{l}\text { Died } 4 \text { months after } \\
\text { (esophageal cancer) }\end{array}$ \\
\hline Haresh et al., 2009 ${ }^{[37]}$ & 17 , male & Visual change & Sellar/suprasellar & Resection + RT & Skull and femur metastasis \\
\hline Thakar et al., $2011^{[38]}$ & 40, male & Visual defect & Frontal lobe & Resection & Recurrence (6 months) \\
\hline Prajsnar et al., 2011 ${ }^{[39]}$ & 53 , female & Trigeminal neuralgia & Meckel's cave & Resection & Recurrence (2 years) \\
\hline Albert et al., 2011[40] & 63 , male & Proptosis & Sellar/parasellar & Resection + RT & Improved \\
\hline Nascimento et al., $2012^{[41]}$ & 33 , female & Endocrine dysfunction & Sellar & Resection & Diabetes insipidus \\
\hline Chaudhry et al., 2013 $3^{[42]}$ & 44 , male & Visual defect & Sellar/suprasellar & Resection & No recurrence \\
\hline
\end{tabular}

${ }^{*}$ Found in Yamauchi et al. review of literature, 1999. RT: radiation therapy

component makes it unique and the first of this type. The radiological features were not conclusive for primary malignant paraganglioma as only extracranial primary malignant forms are known. In addition, the tumor was not functional, and it did not associate with any hemodynamic changes intra-operatively to alert for 
possible active paraganglioma. Although the resection was complete, but the functional deconditioning that can be attributed to postoperative bleeding impeded early adjuvant therapy.

Radiation therapy for local control has been proposed for incomplete resection of benign paraganglioma. There seems to be a better response to radiosurgery than external beam radiation therapy for such lesions. The treatment is being delivered at a range of 12-15 Gy to the tumor margin. ${ }^{[44]}$ We would have planned similar treatment for our patient if she was in a better functional state. Chemotherapy appears to play a role in terms of stabilizing the disease and in some it may lead to reduction in tumor size. This could not be applied to our case given the low KPS and stable tumor bed on serial imaging follow-up.

Even with treatment, the prognosis of malignant paraganglioma remains dismal with 50\% reported mortality in 5 years. ${ }^{[45]}$ However, such data were reported for extracranial paraganglioma/pheochromocytoma and we still do not know if this can be applied for intracerebral primary lesions, which are similar to our case. We suggest that such tumors should be treated with upfront postoperative radiation therapy, preferably radiosurgery. Similarly, it is worth considering delivering chemotherapy based on postoperative resection and risk for future recurrence.

\section{REFERENCES}

1. Hu K, Persky MS. Multidisciplinary management of paragangliomas of the head and neck, Part 1. Oncology (Williston Park) 2003;17:983-93.

2. Kamalian N, Abbassioun K, Amirjamshidi A, Shams-Shahrabadi M. Paraganglioma of the filum terminale internum. Report of a case and review of the literature. $J$ Neurol 1987;235:56-9.

3. Chen H, Sippel RS, O'Dorisio MS, Vinik AI, Lloyd RV, Pacak K; North American Neuroendocrine Tumor Society (NANETS). The North American Neuroendocrine Tumor Society consensus guideline for the diagnosis and management of neuroendocrine tumors: pheochromocytoma, paraganglioma, and medullary thyroid cancer. Pancreas 2010;39:775-83.

4. Amar L, Bertherat J, Baudin E, Ajzenberg C, Bressac-de Paillerets B, Chabre O, Chamontin B, Delemer B, Giraud S, Murat A, Niccoli-Sire P, Richard S, Rohmer V, Sadoul JL, Strompf L, Schlumberger M, Bertagna X, Plouin PF, Jeunemaitre X, Gimenez-Roqueplo AP. Genetic testing in pheochromocytoma or functional paraganglioma. J Clin Oncol 2005;23:8812-8.

5. Lu JQ, Khalil M, Hu W, Sutherland GR, Clark AW. Tumor-to-tumor metastasis: esophageal carcinoma metastatic to an intracranial paraganglioma. J Neurosurg 2009;110:744-8.

6. Ellis RJ, Patel D, Prodanov T, Nilubol N, Pacak K, Kebebew E. The presence of SDHB mutations should modify surgical indications for carotid body paragangliomas. Ann Surg 2014;260:158-62

7. Lee KY, Oh YW, Noh HJ, Lee YJ, Yong HS, Kang EY, Kim KA, Lee NJ. Extraadrenal paragangliomas of the body: imaging features. AJR Am J Roentgenol 2006;187:492-504.

8. Noble ER, Smoker WR, Ghatak NR. Atypical skull base paragangliomas. AJNR Am J Neuroradiol 1997;18:986-90.

9. Mokry M, Kleinert R, Clarici G, Obermayer-Pietsch B. Primary paraganglioma simulating pituitary macroadenoma: a case report and review of the literature. Neuroradiology 1998;40:233-7.

10. Kruse F Jr. Petrous ridge chemodectoma (nonchromaffin paraganglioma) simulating meningioma. Case report. J Neurosurg 1960;17:1108-11.

11. Smith WT, Hughes B, Ermocilla R. Chemodectoma of the pineal region, with observations on the pineal body and chemoreceptor tissue. J Pathol Bacteriol 1966;92:69-76.

12. Chytil S. A case of nonchromaffin paraganglioma originating in the suprasellar region and invading the nose through the sphenoid sinus. Cesk Otolaryngol 1967;16:115-9.

13. Bilbao JM, Horvath E, Kovacs K, Singer W, Hudson AR. Intrasellar paraganglioma associated with hypopituitarism. Arch Pathol Lab Med 1978;102:95-8

14. Ho KC, Meyer G, Garancis J, Hanna J. Chemodectoma involving the cavernous sinus and semilunar ganglion. Hum Pathol 1982;13:942-3.

15. Prabhakar S, Sawhney IM, Chopra JS, Kak VK, Banerjee AK Hemibase syndrome: an unusual presentation of intracranial paraganglioma. Surg Neurol 1984;22:39-42.

16. Steel TR, Dailey AT, Born D, Berger MS, Mayberg MR Paragangliomas of the sellar region: report of two cases. Neurosurgery 1993;32:844-7.

17. Flint EW, Claassen D, Pang D, Hirsch WL. Intrasellar and suprasellar paraganglioma: CT and MR findings. AJNR Am J Neuroradiol 1993;14:1191-3.

18. Scheithauer BW, Parameswaran A, Burdick B. Intrasellar paraganglioma: report of a case in a sibship of von Hippel-Lindau disease. Neurosurgery 1996;38:395-9.

19. Nishitani M, KS, Watabe Y, Chige S, Fujimoto K, Aketa S, Fushimi H. A case of sellar paraganglioma. Horumon Rinsho 1996;45:172-4.

20. Del Basso De Caro ML, Siciliano A, Cappabianca P, Alfieri A, de Divitiis E. Intrasellar paraganglioma with suprasellar extension: case report. Tumori 1998;84:408-11.

21. Sambaziotis D, Kontogeorgos G, Kovacs K, Horvath E, Levedis A. Intrasellar paraganglioma presenting as nonfunctioning pituitary adenoma. Arch Pathol Lab Med 1999;123:429-32.

22. Yamauchi T, Kubota M, Saeki N, Aihara N, Iwadate Y, Yamaura A Paraganglioma in the frontal skull base-case report. Neurol Med Chir (Tokyo) 1999;39:308-12.

23. Reithmeier T, Gumprecht H, Stölzle A, Lumenta CB. Intracerebral paraganglioma. Acta Neurochir (Wien) 2000;142:1063-6.

24. Laquis SJ, Vick V, Haik BG, Fleming JC, Wilson MW. Intracranial paraganglioma (glomus tumor) with orbital extension. Ophthal Plast Reconstr Surg 2001;17:458-61.

25. Salame K, Ouaknine GE, Yossipov J, Rochkind S. Paraganglioma of the pituitary fossa: diagnosis and management. $J$ Neurooncol 2001:54:49-52

26. Hertel F, Bettag M, Mörsdorf M, Feiden W. Paragangliomas of the parasellar region. Neurosurg Rev 2003;26:210-4.

27. Yokoo H, Tanaka G, Isoda K, Hirato J, Nakazato Y, Fujimaki H, Watanabe K, Saito N, Sasaki T. Novel crystalloid structures in suprasellar paraganglioma. Clin Neuropathol 2003;22:222-8.

28. Arkha Y, Boutarbouch M, Lamalmi N, Halefadl S, Laamarti A Derraz S, Aghzadi A, El Ouahabi A, El Khamlichi A. Paraganglioma of the latero-sellar area. Case report. Neurochirurgie 2003;49:540-4

29. Riopel C, Courville P, Fabre B, Callonnec F, Bolognini B, Marie JP, Laquerriere A. Parasellar paraganglioma: a case report. Ann Pathol 2004;24:62-7.

30. Naggara O, Varlet P, Page P, Oppenheim C, Meder JF. Suprasellar paraganglioma: a case report and review of the literature. Neuroradiology 2005;47:753-7.

31. Zorlu F, Selek U, Ulger S, Donmez T, Erden E. Paraganglioma in sella. J Neurooncol 2005;73:265-7.

32. Boari N, Losa M, Mortini P, Snider S, Terreni MR, Giovanelli M Intrasellar paraganglioma: a case report and review of the literature. Acta Neurochir (Wien) 2006;148:1311-4.

33. Peltier J, Fichten A, Lefranc M, Grunewald P, Thelu F, Toussaint P, 
Desenclos C, Le Gars D. Paraganglioma of the cavernous sinus. Case report. Neurochirurgie 2007;53:391-4.

34. Sinha S, Sharma MC, Sharma BS. Malignant paraganglioma of the sellar region mimicking a pituitary macroadenoma. J Clin Neurosci 2008; 15:937-9.

35. Yoo JH, Rivera A, Naeini RM, Yedururi S, Bayindir P, Megahead H, Fuller GN, Suh JS, Adesina AM, Hunter JV. Melanotic paraganglioma arising in the temporal horn following Langerhans cell histiocytosis. Pediatr Radiol 2008;38:571-4.

36. Ozüm U, Egilmez R, Yildirim A. Paraganglioma in pituitary fossa. Neuropathology 2008;28:547-50.

37. Haresh KP, Prabhakar R, Anand Rajan KD, Sharma DN, Julka PK, Rath GK. A rare case of paraganglioma of the sella with bone metastases. Pituitary 2009;12:276-9.

38. Thakar S, Ghosal N, PS, Gupta K, Hegde AS. A supratentorial primary parenchymal paraganglioma. J Clin Neurosci 2011;18:986-8.

39. Prajsnar A, Balak N, Walter GF, Stan AC, Deinsberger W, Tapul L, Bayindir C. Recurrent paraganglioma of Meckel's cave: case report and a review of anatomic origin of paragangliomas. Surg Neurol Int 2011;2:45

40. Albert A, Ramirez JA, Codere F, Petrecca K. Sellar paraganglioma: a unique route to a rare destination case report and literature review. Clin Neurol Neurosurg 2011;113:675-7.

41. do Nascimento A, Maranha LA, Corredato RA, Araújo JC,
Bleggi-Torres LF. 33 year-old woman with a large sellar tumor. Brain Pathol 2012;22:869-70.

42. Chaudhry NS, Ahmad F, Blieden C, Morcos JJ. Suprasellar and sellar paraganglioma presenting as a nonfunctioning pituitary macroadenoma. J Clin Neurosci 2013;20:1615-8.

43. Voulgaris SG, Partheni M, Tzortzidis F, Ravazoula P, Pessach IS, Papadakis N, Papadakis N, Polyzoidis KS. Suprasellar and intrasellar paragangliomas. Clin Neuropathol 2006;25:221-6.

44. van Hulsteijn LT, Corssmit EP, Coremans IE, Smit JW, Jansen JC, Dekkers OM. Regression and local control rates after radiotherapy for jugulotympanic paragangliomas: systematic review and meta-analysis. Radiother Oncol 2013;106:161-8.

45. van Hulsteijn LT, Niemeijer ND, Dekkers OM, Corssmit EP. (131) I-MIBG therapy for malignant paraganglioma and phaeochromocytoma: systematic review and meta-analysis. Clin Endocrinol (Oxf) 2014;80:487-501.

Cite this article as: Al Jishi AA, Lach B, Elgheriani A, Kachur E, Cenic A. Primary supratentorial intracerebral malignant paraganglioma. Neuroimmunol Neuroinflammation 2015;2(2):121-6.

Source of Support: Nil. Conflict of Interest: No.

Received: 13-09-2014; Accepted: 23-12-2014 